\title{
The Italian multicentre study on noninvasive ventilation in chronic obstructive pulmonary disease patients
}

\author{
E. Clini*, C. Sturani\#, A. Rossi", S. Viaggi ${ }^{+}$, A. Corrado ${ }^{\S}$, C.F. Donner ${ }^{f}$, N. Ambrosino**, \\ on behalf of the Rehabilitation and Chronic Care Study Group, Italian Association of Hospital \\ Pulmonologists (AIPO)
}

The Italian multicentre study on noninvasive ventilation in chronic obstructive pulmonary disease patients. E. Clini, C. Sturani, A. Rossi, S. Viaggi, A. Corrado, C.F. Donner, N. Ambrosino, on behalf of the Rehabilitation and Chronic Care Study Group, Italian Association of Hospital Pulmonologists ( AIPO). (C) ERS Journals Ltd 2002.

ABSTRACT: Chronic obstructive pulmonary disease (COPD) patients with chronic ventilatory failure (CVF) are more likely to develop exacerbations, which are an important determinant of health-related quality of life (HRQL). Long-term noninvasive positive-pressure ventilation (NPPV) has been proposed in addition to long-term oxygen therapy (LTOT) to treat CVF but little information is available on its effects on HRQL and resource consumption. Therefore, the current authors undertook a 2-yr multicentric, prospective, randomised, controlled trial to assess the effect of NPPV+ LTOT on: 1) severity of hypercapnia; 2) use of healthcare resources, and 3) HRQL, in comparison with LTOT alone.

One hundred and twenty-two stable hypercapnic COPD patients on LTOT for $\geqslant 6$ months were consecutively enrolled. After inclusion and 1-month run-in, 90 patients were randomly assigned to NPPV + LTOT $(n=43)$ or to LTOT alone $(n=47)$. Arterial blood gases, hospital and intensive care unit (ICU) admissions, total hospital and ICU length of stay and HRQL were primary outcome measures; survival and drop-out rates, symptoms (dyspnoea and sleep quality) and exercise tolerance were secondary outcome measures. Follow-up was performed at 3-month intervals up to 2 yrs.

Lung function, inspiratory muscle function, exercise tolerance and sleep quality score did not change over time in either group. By contrast the carbon dioxide tension in arterial blood on usual oxygen, resting dyspnoea and HRQL, as assessed by the Maugeri Foundation Respiratory Failure Questionnaire, changed differently over time in the two groups in favour of NPPV+LTOT. Hospital admissions were not different between groups during the follow-up. Nevertheless, overall hospital admissions showed a different trend to change in the NPPV+LTOT (decreasing by $45 \%$ ) as compared with the LTOT group (increasing by $\mathbf{2 7} \%$ ) when comparing the follow-up with the followback periods. ICU stay decreased over time by $75 \%$ and $20 \%$ in the NPPV+LTOT and LTOT groups, respectively. Survival was similar.

Compared with long-term oxygen therapy alone, the addition of noninvasive positivepressure ventilation to long-term oxygen therapy in stable chronic obstructive pulmonary disease patients with chronic ventilatory failure: 1) slightly decreased the trend to carbon dioxide retention in patients receiving oxygen at home and 2) improved dyspnoea and health-related quality of life. The results of this study show some significant benefits with the use of nocturnal, home noninvasive positive-pressure ventilation in patients with chronic ventilatory failure due to advanced chronic obstructive pulmonary disease patients. Further work is required to evaluate the effect of noninvasive positive-pressure ventilation on reducing the frequency and severity of chronic obstructive pulmonary disease exacerbation.

Eur Respir J 2002; 20: 529-538.
*Division of Pulmonary Rehabilitation, Fondazione Villa Pineta ONLUS, Pavullo (MO), " Pulmonary Division, Carlo Poma Hospital, Mantova, 'Pulmonary Division, Ospedali Riuniti, Bergamo, ${ }^{7}$ Unit of Biostatistics, Qubisoft, Padova, ${ }^{\S}$ Respiratory Intensive Care Unit, Ospedale di Careggi, Firenze, ${ }^{f}$ Pulmonary Division, Salvatore Maugeri Foundation, Scientific Institute of Veruno, Veruno, and **Pulmonary Division, Salvatore Maugeri Foundation, Scientific Institute of Gussago, Gussago, Italy.

Correspondence: N. Ambrosino Pulmonary Rehabilitation Dept Salvatore Maugeri Foundation Scientific Institute of Gussago I- 25064

Gussago (BS)

Italy

Fax: 390302521718

E-mail: nambrosino@fsm.it

Keywords: Chronic obstructive pulmonary disease exacerbations health-related quality of life hypercapnia

mechanical ventilation respiratory failure

respiratory muscles

Received: November 132001 Accepted after revision: April 172002

This study was supported by AIPO (Italian Association of Hospital Pulmonologists) and Markos-Mefar through Air Liquide Group Italia.
Chronic obstructive pulmonary disease (COPD) is currently the fourth leading cause of death in the world, and further increases in the prevalence and mortality of the disease can be predicted in the coming decades [1]. In a hospital accepting acute admissions, up to $20 \%$ of the admissions may be related to COPD exacerbations [2]. Once these patients develop chronic

For editorial comments see page 511. ventilatory failure (CVF), i.e. a condition in which the carbon dioxide tension in arterial blood $\left(\mathrm{Pa}, \mathrm{CO}_{2}\right)$ is persistently $>6 \mathrm{kPa}(45 \mathrm{mmHg})$ with compensated respiratory acidosis, their prognosis worsens and they are more likely to develop exacerbations, be admitted to hospital and/or the intensive care unit (ICU) [3] and experience a deterioration of their disability. As exacerbations are important determinants of healthrelated quality of life (HRQL) [4], there is a need to 
reduce their frequency. However, to date, few interventions have been shown to reduce the frequency of exacerbations in patients with advanced COPD and CVF.

Home long-term oxygen therapy (LTOT) has been shown to improve survival in patients with severe COPD and chronic hypoxaemia [5]. Long-term noninvasive positive pressure ventilation (NPPV) has been proposed, in addition to LTOT, to treat chronic hypercapnia, with the theoretical rationale of improving gas exchange, unloading the respiratory muscles, and resetting the central respiratory drive [6]. However, the evidence for the long-term benefits of NPPV remains rather scarce [7] and a matter of controversy [8]. Even less information is available on the effects on HRQL and healthcare resource consumption.

Therefore, the current authors undertook this 2-yr multicentric, prospective, randomised, controlled study in patients with CVF due to advanced COPD to assess the effect of the addition of NPPV to LTOT in comparison with LTOT alone on: 1) severity of hypercapnia; 2) use of healthcare resources; and 3) HRQL.

\section{Methods}

The investigative protocol was approved by the local ethical committees of all the institutions participating in the study which was conducted according to the declaration of Helsinki. Patients gave their informed consent to participate in the study.

\section{Patients}

One hundred and twenty-two patients with severe COPD as defined by the American Thoracic Society criteria [9] were consecutively enroled in 20 Italian and one French Respiratory Unit between June 1996 and January 2000. The diagnosis of CVF was based on the clinical records showing values of $\mathrm{Pa}_{\mathrm{a}} \mathrm{CO}_{2}>6.6 \mathrm{kPa}$ $(50 \mathrm{mmHg})$ during room air spontaneous breathing in the months if not years preceding the study. All patients were in stable clinical condition, as assessed by an arterial $\mathrm{pH}>7.35$, and were free from exacerbation in the 4 weeks preceding recruitment. Patients were included if they met the following criteria: age $\leqslant 75$ yrs, LTOT for at least 6 months, dyspnoea score as assessed by the Medical Research Council (MRC) score $\geqslant 2$ [10], forced expiratory volume in one second $(\mathrm{FEV} 1)<1.5 \mathrm{~L}, \mathrm{FEV} 1$ to forced vital capacity ratio $<60 \%$, total lung capacity $\geqslant 90 \%$ predicted, $\mathrm{Pa}_{\mathrm{a}} \mathrm{CO}_{2}$ $>6.6 \mathrm{kPa}(50 \mathrm{mmHg})$ and arterial oxygen tension $\left(P \mathrm{a}, \mathrm{O}_{2}\right)<7.8 \mathrm{kPa}(60 \mathrm{mmHg})$ breathing room air at rest. Patients were excluded if they had: a $15 \%$ increase in FEV1 after inhaled salbutamol $(200 \mu \mathrm{g})$, $\mathrm{pH} \leqslant 7.34$, active smoking, documented history of obstructive sleep apnoea syndrome as defined by an apnoea/hypopnoea index $>10$ episodes $\cdot \mathrm{h}^{-1}$ during polysomnography, therapy with systemic steroids, important concomitant chronic systemic diseases (i.e. chronic heart failure, diabetes, infections, neoplasm, etc), other chronic respiratory diseases (e.g. significant fibrothorax, bronchiectasis, cystic fibrosis), previous or concomitant NPPV or participation in any homecare program apart from LTOT.

All patients received regular treatment (bronchodilators) adjusted to achieve optimal symptomatic control and were strongly encouraged to remain active; all of them received anticholinergics; other drugs including topical steroids, if any, were recorded on a diary card. Antibiotics and systemic steroids were prescribed, when requested, by the patient's general practitioner (GP) who also decided hospitalisation when necessary.

\section{Measurements}

All physiological measurements were performed by personnel blind to treatment and not involved in the study.

Lung and respiratory muscle function. Routine static and dynamic lung volumes were measured with constant volume body plethysmograph with the patients in the seated position according to standard procedure [11]. The predicted values of QUANJER et al. [12] were used. Arterial blood was sampled at the radial artery while the patients were in semirecumbent position, both breathing room air and on their usual oxygen flow. $\mathrm{Pa}, \mathrm{O}_{2}, \mathrm{~Pa}_{1} \mathrm{CO}_{2}$ and $\mathrm{pH}$ were measured by means of automated analysers. The inspiratory muscle strength was assessed by measuring maximal inspiratory pressure at the level of functional residual capacity, according to the method of BLACK and HyATT [13]. The highest of three reproducible attempts was recorded.

Dyspnoea and exercise tolerance. Resting dyspnoea was assessed by the MRC score [10]. Exercise capacity was assessed by the 6-min walking distance test (6MWD) [14] while patients breathed room air. Verbal encouragement was given at definite intervals during the test. Three practice tests were performed on 2 consecutive days and the highest value was recorded. All measurements were performed and recorded under the supervision of a nurse not involved in the study. Arterial oxygen saturation $\left(\mathrm{Sa}_{\mathrm{a}} \mathrm{O}_{2}\right)$ was monitored throughout the walk using a pulse oximeter and the lowest value was recorded.

Sleep study. Sleep was evaluated [15] by monitoring pulse oxymetry, heart rate, oronasal flow and body position, while patients breathed their usual prescribed oxygen flow. The quality of sleep was assessed by means of a semiqualitative multipoint scale with a range 1 (best) to 4 (worst) [16].

Health-related quality of life. HRQL was assessed by validated Italian versions of the St. George's Respiratory Questionnaire (SGRQ) [17] and of the Maugeri Foundation Respiratory Failure Questionnaire (MRF-28) [18].

Hospitalisations. Number and location of hospital admissions, total hospital stay (days) in the previous 3 yrs (follow-back) were recorded. These data were 
obtained by patient interview at admission, from the hospital registers and by interview of the patient's relatives or GP. Follow-up hospitalisations were decided by the patient's GP, who was aware of but not participating in the study. Patients were asked to record hospital admissions for the 2 yrs following inclusion in the study. Neither exacerbations treated in the community nor the extra therapy taken at exacerbations were recorded. Finally, mortality rate was recorded in the follow-up.

Treatment compliance. Actual time spent on NPPV and LTOT was recorded at each visit during the follow-up. The use of the ventilator was obtained from the time counter, and reported use was obtained from daily cards. Daily use of LTOT was assessed by asking the patient and his/her relatives; a cross check was then performed with the report of homecare companies responsible for LTOT.

Ventilatory support. The modality of NPPV was pressure support ventilation (PSV), delivered by a BiPAP-ST30 "auto-trak"TM ventilator (Respironics Inc, Murrysville, PA, USA, distributed in Italy by Markos-Mefar, Air Liquide Group) through a nasal mask (Respironics Inc). The commercial masks were of adequate size to fit to each patient's nose. A one-way circuit was provided with a plateau exhalation valve to avoid rebreathing [19]. The ventilator was set in spontaneous/timed mode, as previously described [20], at the maximal tolerated inspiratory positive airway pressure (IPAP) and at an expiratory positive airway pressure (EPAP) tolerated in the range of 2-5 $\mathrm{cmH}_{2} \mathrm{O}$, with a back-up respiratory rate of 8 breaths $\cdot \mathrm{min}^{-1}$. Oxygen was added to the mask side-port at a flow able to achieve a target $S \mathrm{a}, \mathrm{O}_{2} \geqslant 90 \%$. Effectiveness of NPPV had to be proven by a $5 \%$ decrease in $\mathrm{Pa}_{\mathrm{a}} \mathrm{CO}_{2}$ after $1 \mathrm{~h}$ of continuous support and by night-time oxymetry; NPPV was considered as effective when patients spent $>90 \%$ of recording time with $\mathrm{Sa}_{\mathrm{a}} \mathrm{O}_{2} \geqslant 90 \%$ under NPPV. Both criteria were achieved in all patients.

Study design. This was a parallel-group, controlled, randomised study. After inclusion (M-1), all patients were followed as outpatients for 1 month (run-in). At the end of the run-in period (M0), patients still meeting all the inclusion criteria above and showing a change in arterial blood gases $<10 \%$ from baseline values independent of the cut-off limit $(6.6 \mathrm{kPa})$ for inclusion, were admitted to hospital and randomised to have NPPV added to LTOT or to continue their usual LTOT (max eight per centre). Because of the small number of eligible patients in each centre, a centralised randomisation was used. Blocks were used to provide balanced groups in the overall enrolment (not inside each centre).

Patients of both groups received the same inhospital management including NPPV trial before randomisation. Therefore, all patients underwent 10night NPPV trials before randomisation. Patients were instructed to use the ventilator overnight for $\geqslant 5 \mathrm{~h} \cdot$ night $^{-1}$ throughout the study period. After randomisation, close contact was maintained with all randomised patients of both groups and their relatives at home, in order to ensure good compliance to both NPPV+LTOT and to LTOT alone. A phone number was provided to all patients if they had any problems. Technically skilled personnel performed installation of the NPPV apparatus in the patient's home and provided periodic controls throughout the study period.

Follow-up was performed one month after discharge (M1) and at 3-month intervals up to 2 yrs (M3-M24). Table 1 shows the panel of evaluations at each follow-up step.

Definitions. Henceforth NPPV group indicates the treatment group $(n=43)$ undergoing NPPV+LTOT, while LTOT group indicates the control group $(n=47)$ receiving LTOT alone. Compliance to NPPV was defined as the use of ventilator for $\geqslant 5 \mathrm{~h} \cdot$ night $^{-1}$; compliance to LTOT was defined by $\geqslant 15 \mathrm{~h} \cdot$ day $^{-1}$ use. Patients not compliant to NPPV or refusing their consent within 10 days after randomisation (before discharge from the hospital) were defined as "early drop-outs" and replaced. A "drop-out" was defined as a patient who refused to continue the protocol, showed any exclusion criteria, or was not compliant to therapy after 10 days from randomisation (after discharge).

\section{Statistical analysis}

Sample size. Although this study addresses several outcome measures, only one was considered for sample size determination. Changes in daytime $\mathrm{Pa}_{\mathrm{a}} \mathrm{CO}_{2}$ under usual oxygen breathing was the outcome selected for determining a minimum sample size able to ensure powerful testing on treatment effect. In order to ensure $80 \%$ power to detect a $0.66 \mathrm{kPa}(5 \mathrm{mmHg})$ reduction in $\mathrm{Pa}, \mathrm{CO}_{2}$ (from 7.23 to $6.57 \mathrm{kPa}$ (55 to $50 \mathrm{mmHg}$ ) mean, SD 0.66 ) as significant at the 0.05 level, $\geqslant 17$ patients per group were needed for the study. Considering a probability of $30 \%$ drop-out rate of randomised patients, minimum target sample size was fixed at 25 patients per group.

Efficacy analysis and intention to treat. The main parameters were evaluated both in terms of patient completers and in terms of the intention to treat approach (ITT). Last observation carried forward was used as a method of ITT and data are presented accordingly. Time controls recorded in the analysis were baseline, 12 and 24 months. Data on patients' compliance were evaluated only in terms of patient completers in order to document "per protocol" analysis.

Arterial blood gases (ABG), HRQL questionnaires, lung function tests, Borg scale, and MRC dyspnoea scale were evaluated with analysis of variance (oneway ANOVA) on group differences from baseline. ANOVA models were applied to ITT analysis in order to detect group differences.

The 6MWD test was also evaluated with a nonparametric approach, coding changes from baseline at 12 and 24 months. Fisher's exact test was used to compare percentages of changes between groups. 
Table 1.-Evaluations during the study period

\begin{tabular}{|c|c|c|c|c|c|c|c|c|c|c|c|}
\hline & \multicolumn{11}{|c|}{ Time related to discharge } \\
\hline & M-1 & M0 & M1 & M3 & M6 & M9 & M12 & M15 & M18 & M21 & M24 \\
\hline Physical examination & $\checkmark$ & $\checkmark$ & $\checkmark$ & $\checkmark$ & $\checkmark$ & $\checkmark$ & $\checkmark$ & $\checkmark$ & $\checkmark$ & $\checkmark$ & $\checkmark$ \\
\hline Dyspnoea score & $\checkmark$ & $\checkmark$ & & & $\checkmark$ & & $\checkmark$ & & $\checkmark$ & & $\checkmark$ \\
\hline $\mathrm{ABG}$ & $\checkmark$ & $\checkmark$ & $\checkmark$ & $\checkmark$ & $\checkmark$ & $\checkmark$ & $\checkmark$ & $\checkmark$ & $\checkmark$ & $\checkmark$ & $\checkmark$ \\
\hline Spirometry & $\checkmark$ & $\checkmark$ & & & $\checkmark$ & & $\checkmark$ & & $\checkmark$ & & $\checkmark$ \\
\hline MIP & $\checkmark$ & $\checkmark$ & & & $\checkmark$ & & $\checkmark$ & & $\checkmark$ & & $\checkmark$ \\
\hline Biochemistry & $\checkmark$ & $\checkmark$ & & & & & $\checkmark$ & & & & $\checkmark$ \\
\hline Chest radiography & $\checkmark$ & $\checkmark$ & & & & & $\checkmark$ & & & & $\checkmark$ \\
\hline ECG & & $\checkmark$ & & & & & $\checkmark$ & & & & $\checkmark$ \\
\hline 6MWD & & $\checkmark$ & & & & & $\checkmark$ & & & & $\checkmark$ \\
\hline Sleep quality score & & $\checkmark$ & $\checkmark$ & & $\checkmark$ & & $\checkmark$ & & $\checkmark$ & & $\checkmark$ \\
\hline Polysomnography & & $\checkmark$ & & & & & & & & & \\
\hline MRF-28 & & $\checkmark$ & & & & & $\checkmark$ & & & & $\checkmark$ \\
\hline SGRQ & & $\checkmark$ & & & & & $\checkmark$ & & & & $\checkmark$ \\
\hline CT scan" & & $\checkmark$ & & & & & & & & & \\
\hline Echocardiography ${ }^{\#}$ & & $\checkmark$ & & & & & $\checkmark$ & & & & $\checkmark$ \\
\hline Drugs check & $\checkmark$ & $\checkmark$ & $\checkmark$ & $\checkmark$ & $\checkmark$ & $\checkmark$ & $\checkmark$ & $\checkmark$ & $\checkmark$ & $\checkmark$ & $\checkmark$ \\
\hline Side-effects & & & $\checkmark$ & $\checkmark$ & $\checkmark$ & $\checkmark$ & $\checkmark$ & $\checkmark$ & $\checkmark$ & $\checkmark$ & $\checkmark$ \\
\hline Hospitalisation & & & $\checkmark$ & $\checkmark$ & $\checkmark$ & $\checkmark$ & $\checkmark$ & $\checkmark$ & $\checkmark$ & $\checkmark$ & $\checkmark$ \\
\hline Treatment compliance & & & $\checkmark$ & $\checkmark$ & $\checkmark$ & $\checkmark$ & $\checkmark$ & $\checkmark$ & $\checkmark$ & $\checkmark$ & $\checkmark$ \\
\hline
\end{tabular}

M: months; M0: discharge; ABG: arterial blood gas analysis; MIP: maximal inspiratory pressure; ECG: electrocardiogram; 6MWD: 6-min walking distance test; MRF-28: Maugeri Foundation Respiratory Failure Questionnaire; SGRQ: St George's Respiratory Questionnaire; CT: computed tomography. ${ }^{\#}$ : optional.

No correction for multiple testing was made in the statistical analysis. Although the study addressed several outcomes, the current authors were unable to predict in which ones a clear treatment effect would be found.

Hospitalisations. Number of hospitalisations, and number of hospital days were calculated according to time in the study and normalised per year. ICU admissions and length of stay were also considered. In order to take into account hospitalisation frequency before the start of the study, previous hospitalisations. $\mathrm{yr}^{-1}$ and hospital days $\cdot \mathrm{yr}^{-1}$ were provided and considered as "baseline". Two linear models were utilised to compare these rates between groups. ANOVA was used to compare groups on differences in rates from "baseline" (prestudy values); analysis of covariance was used to adjust study rates according to "baseline" rates, so testing differences in group rates conditionally to equal overall "baseline" values.

Survival analysis. Differences in survival rates between groups were evaluated with the Kaplan-Meier approach. The Wilcoxon and log-rank tests of equality over strata were utilised.

Drop-out rate. In order to compare treatment groups on the length of time patients remained in the study, a Kaplan-Meier approach was used. Log-rank and Wilcoxon tests were utilised to compare drop-outs between groups.

General considerations. All tests were considered two tailed, with $\alpha=0.05$, without correction for multiple testing.

\section{Results}

\section{Randomisation}

The trial profile is shown in figure 1. Among the 122 patients included in the study, six were excluded from randomisation because they did not meet criteria for postbronchodilator reversibility, another 26 were excluded as they showed a $\mathrm{Pa}, \mathrm{CO}_{2}$ change $>10 \%$ of baseline value at the end of the run-in period. Characteristics of 90 patients randomised after run-in (not

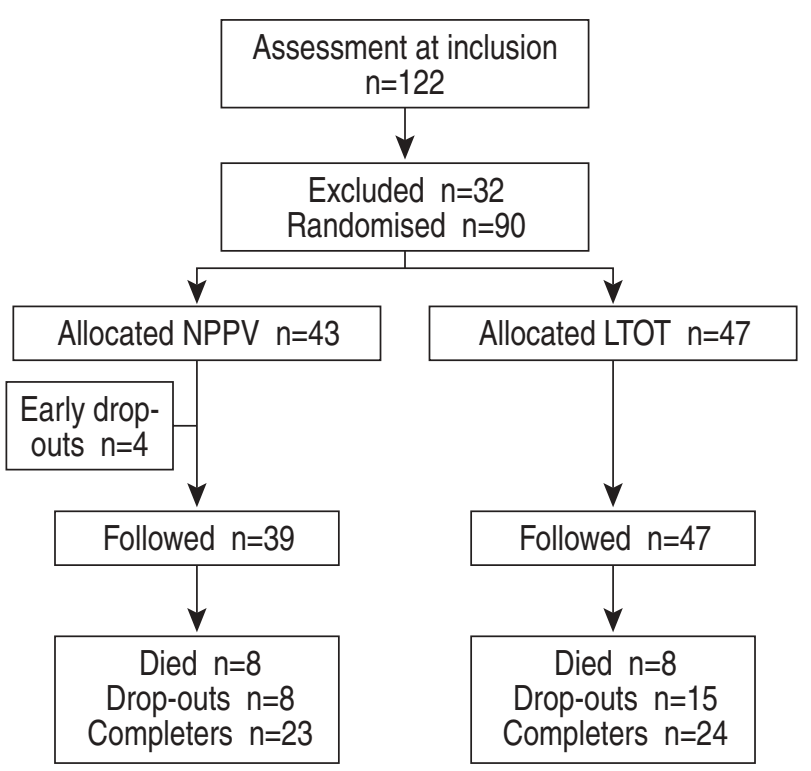

Fig. 1.- Trial profile. NPPV: noninvasive positive-pressure ventilation and long-term oxygen therapy; LTOT: long-term oxygen therapy alone. 
including four early drop-outs) are shown in table 2 . At M0 there were no significant differences between groups. Early drop-outs were not different from other subjects.

\section{Treatment compliance}

Mean daily LTOT use was $19 \pm 1$ and $20 \pm 2 \mathrm{~h}$ in NPPV and LTOT groups, respectively. Mean daily use of ventilator in the compliant patients of the NPPV group was $9 \pm 2 \mathrm{~h}$. On average, the NPPV setting was: IPAP $14 \pm 3$ and EPAP $2 \pm 1 \mathrm{cmH}_{2} \mathrm{O}$, respectively.

\section{Drop-out and survival rates}

The drop-out rate during follow-up was similar in the two groups. Eight and 15 patients dropped out in the NPPV and LTOT groups, respectively: causes were related to noncompliance to oxygen (one patient among LTOT) or to ventilator use (three patients among NPPV), voluntary withdrawal from the study (four and two patients in LTOT and NPPV, respectively), new diagnosed neoplasm (two and one patients in LTOT and NPPV, respectively), lost to follow-up (seven and one patients in LTOT and NPPV, respectively), tracheostomy (one patient in both LTOT and NPPV groups). Baseline characteristics

Table 2. - Demographic, anthropometric, lung function and clinical characteristics of patients at randomisation

\begin{tabular}{lcc}
\hline Characteristics & NPPV group & LTOT group \\
\hline Subjects n & 39 & 47 \\
Sex M:F & $32: 7$ & $37: 10$ \\
Age yrs & $64 \pm 7$ & $66 \pm 14$ \\
BMI & $26 \pm 5$ & $25 \pm 6$ \\
Cigarette smoking & $29 \pm 6$ & $26 \pm 5$ \\
pack-yrs & $27 \pm 8$ & \\
FEV $\%$ pred. & $55 \pm 17$ & $31 \pm 11$ \\
VC \% pred. & $193 \pm 78$ & $62 \pm 15$ \\
RV \% pred. & $118 \pm 29$ & $178 \pm 48$ \\
TLC \% pred. & $200 \pm 125$ & $110 \pm 16$ \\
6MWD m & $50 \pm 20$ & $247 \pm 110$ \\
MIP cmH ${ }_{2} \mathrm{O}$ & $7.39 \pm 0.04$ & $46 \pm 21$ \\
pH & $7.2 \pm 0.6$ & $7.39 \pm 0.03$ \\
$P$ a,CO $\mathrm{kPa}^{\#}$ & $6.7 \pm 0.8$ & $7.4 \pm 0.6$ \\
$P \mathrm{a}, \mathrm{O}_{2} \mathrm{kPa}^{\#}$ & $19 \pm 20$ & $6.6 \pm 0.8$ \\
$\mathrm{Hospital} \mathrm{stays}$ & & $18 \pm 18$ \\
day $\cdot$ patient $^{-1} \cdot \mathrm{yr}^{-1}$ & $66 \pm 14$ & $62 \pm 21$ \\
SGRQ total score & $30 \pm 22$ & $29 \pm 23$ \\
LTOT months & & \\
\hline
\end{tabular}

Data are presented as mean \pm SD. NPPV: noninvasive positive-pressure ventilation and long-term oxygen therapy; LTOT: long-term oxygen therapy; M: male; F: female; BMI: body mass index; FEV1: forced expiratory volume in one second; VC: vital capacity; RV: residual volume; TLC: total lung capacity; 6MWD: 6-min walking distance test; MIP: maximal inspiratory pressure; $P \mathrm{a}_{2}, \mathrm{CO}_{2}$ : carbon dioxide tension in arterial blood; $\mathrm{Pa}_{\mathrm{a}} \mathrm{O}_{2}$ : oxygen tension in arterial blood; SGRQ: St George's Respiratory Questionnaire. ${ }^{\#}$ : breathing room air; ${ }^{\uparrow}$ : year mean data for the 3 yrs before the study. of drop-outs of either group were not different from those of patients completing the study.

Mortality rate was similar in the two groups (18 and $17 \%$ in NPPV and LTOT, respectively). Deaths were due to acute respiratory failure (three and five patients in LTOT and NPPV groups, respectively), cardiac failure (one patient in both LTOT and NPPV groups) and other acute diseases (four and two patients in LTOT and NPPV, respectively).

\section{Clinical and physiological assessments}

Table 3 shows the time course of the main physiological variables during the study period. Pulmonary function, inspiratory muscle strength, exercise tolerance and sleep quality score did not significantly change over time in either group, although the sleep score showed a slight trend to improve in NPPV patients.

Figure 2 shows the changes in $\mathrm{ABG}$ over time. $P$ a, $\mathrm{CO}_{2}$, measured on patients' usual oxygen regimen (fig. 2d), increased in patients receiving LTOT alone, whereas it decreased in patients receiving NPPV. Although the change was small (though of opposite direction) in the two groups compared to baseline, i.e. $0.26 \mathrm{kPa}(2 \mathrm{mmHg})$ on average, the difference between the two groups widened from $0.13 \mathrm{kPa}$ at the beginning of the study to $0.66 \mathrm{kPa}(1-5 \mathrm{mmHg})$, such that after $2 \mathrm{yrs}$ of treatment $\mathrm{Pa}_{\mathrm{a}} \mathrm{CO}_{2}$ on oxygen averaged 7.23 and $7.89 \mathrm{kPa}(55$ and $60 \mathrm{mmHg})$ in NPPV and LTOT groups, respectively. Figure 2 also clearly shows a different behaviour over time. $\mathrm{Pa}, \mathrm{CO}_{2}$ exhibited a tendency to increase in LTOT patients, whereas it consistently decreased in NPPV patients. No significant difference between groups was found in ABG during room air breathing (fig. $2 \mathrm{a}$ and c).

Resting dyspnoea, assessed by the MRC scale, significantly improved over time in the NPPV group and at M24 was significantly better than in the LTOT group (fig. 3).

Results of HRQL are illustrated in figure 4. SGRQ total score (fig. 4a and b) showed a trend to improve in both groups $(-5$ and $-4 \%$ in NPPV and LTOT groups, respectively) after 2 yrs, mainly due to improvement in symptoms without any significant differences between groups. In contrast, the MRF-28 total score significantly improved in the NPPV group compared to the LTOT group (fig. $4 \mathrm{c}$ and d).

\section{Hospitalisations}

During the follow-up, hospital admissions $(0.9 \pm 1.2$ and $1.4 \pm 2.3 \mathrm{n} \cdot$ patient $^{-1} \cdot \mathrm{yr}^{-1}$ in NPPV and LTOT, respectively) and ICU admissions (0.2 \pm 0.4 and $0.4 \pm$ $0.8 \mathrm{n} \cdot$ patient $^{-1} \cdot \mathrm{yr}^{-1}$ in NPPV and LTOT, respectively) were not different between groups. Compared with the 3 yrs preceding the study, days spent in hospital after 24 months showed a nonsignificant within-group reduction (from $19.9 \pm 20.2$ to $13.6 \pm 18.3 \mathrm{n} \cdot$ patient $^{-1}$. $\mathrm{yr}^{-1}$; treatment effect 6.996 , 95\% confidence interval $-4.30-18.29, \mathrm{p}=0.2281$ ) in the NPPV but not in the LTOT group (from $18.5 \pm 18.3$ to $19.3 \pm 32.9$ 
Table 3. - Time course of lung volumes, respiratory muscle strength, exercise capacity and sleep quality for both groups

\begin{tabular}{|c|c|c|c|}
\hline & \multicolumn{3}{|c|}{ Time related to discharge } \\
\hline & M0 & M12 & M24 \\
\hline \multicolumn{4}{|l|}{ FEV1 $\%$ pred } \\
\hline NPPV group & $26.6 \pm 8.7$ & $26.8 \pm 8.9$ & $27.5 \pm 10.6$ \\
\hline LTOT group & $31.0 \pm 11.4$ & $30.9 \pm 11.3$ & $30.8 \pm 11.1$ \\
\hline Treatment effect (lower and upper 95\% CI) & & $-0.3(-13.1-+2.4)$ & $-1.1(-4.5-+2.1)$ \\
\hline \multicolumn{4}{|l|}{ VC \% pred } \\
\hline NPPV group & $54.4 \pm 17.2$ & $52.9 \pm 17.0$ & $55.3 \pm 18.2$ \\
\hline LTOT group & $62.1 \pm 14.7$ & $60.0 \pm 14.3$ & $59.8 \pm 12.3$ \\
\hline Treatment effect (lower and upper 95\% CI) & & $-0.7(-6.2-+4.8)$ & $-3.1(-8.1-+1.8)$ \\
\hline \multicolumn{4}{|l|}{$\mathrm{MIP} \mathrm{cmH}_{2} \mathrm{O}$} \\
\hline NPPV group & $50.0 \pm 20.0$ & $50.7 \pm 19.7$ & $50.6 \pm 20.6$ \\
\hline LTOT group & $45.7 \pm 20.9$ & $48.4 \pm 27.5$ & $48.1 \pm 27.2$ \\
\hline Treatment effect (lower and upper 95\% CI) & & $2.1(-3.6-+7.7)$ & $1.8(-4.2-+7.9)$ \\
\hline \multicolumn{4}{|l|}{ 6MWD m } \\
\hline NPPV group & $201 \pm 125$ & $202 \pm 120$ & $183 \pm 118$ \\
\hline LTOT group & $247 \pm 110$ & $244 \pm 108$ & $232 \pm 111$ \\
\hline Treatment effect (lower and upper 95\% CI) & & $-4.4(-37.5-+28.6)$ & $3.3(-39.0-+45.7)$ \\
\hline \multicolumn{4}{|l|}{ Sleep score } \\
\hline NPPV group & $2.5 \pm 1.1$ & $2.0 \pm 0.9$ & $1.7 \pm 0.8$ \\
\hline LTOT group & $2.2 \pm 1.2$ & $2.58 \pm 1.1$ & $2.3 \pm 1.3$ \\
\hline Treatment effect (lower and upper 95\% CI) & & $0.29(0.0-+0.7)$ & $0.31(+0.1-+1.0)$ \\
\hline
\end{tabular}

Data are presented as mean \pm SD. M: month; M0: discharge; FEV1: forced expiratory volume in one second; NPPV: noninvasive positive pressure ventilation and long-term oxygen therapy; LTOT: long-term oxygen therapy alone; CI: confidence interval; VC: vital capacity; MIP: maximal inspiratory pressure; 6MWD: 6-min walking distance test. Patient numbers for analysis of considered variables in NPPV and LTOT groups, respectively: FEV1 39 and 46; VC 39 and 45; MIP 38 and 46; 6MWD 37 and 42; and sleep score 39 and 46.

$\mathrm{n} \cdot$ patient $\left.^{-1} \cdot \mathrm{yr}^{-1}\right)$. Compared with the period before the start of the study, total hospital admissions increased by $27 \%$ in the LTOT group and decreased by $45 \%$ in the NPPV group. ICU admissions decreased more in the NPPV than the LTOT group (by 20\% and 75\% in LTOT and NPPV groups, respectively) although differences between groups were not significant.

\section{Discussion}

Controlled clinical trials of NPPV in stable COPD patients have reported conflicting results regarding short-term clinical and functional outcome [21-24]. Even less data are reported on the long-term effects $[25,26]$. This 2-yr prospective, randomised, controlled study adds important information on the effects of NPPV in COPD patients with CVF.

The data here show that the addition of NPPV to LTOT, compared with LTOT alone: 1) improves daytime $\mathrm{Pa}, \mathrm{CO}_{2}$ levels during oxygen breathing; and 2) improves dyspnoea and HRQL, as assessed by a questionnaire specific for patients with CVF.

\section{Drop-out rate}

Patients with COPD are considered to be less tolerant and/or to gain less benefit from NPPV than most neuromuscular and restrictive patients [6]. CRINER et al. [27] found that only 50\% of COPD patients continued to use NPPV during a prolonged follow-up of $\sim 6$ months, despite enrolment in a comprehensive in-patient and out-patient programme.
The results of the current study differ from the study by CRINER et al. [27]. In the current study, if the training period is excluded, drop-outs due to lack of compliance or voluntary withdrawal from the study were five out of $39(13 \%)$ in the NPPV group and five out of $47(11 \%)$ in the LTOT group, respectively. With the limitation of an experimental setting and its peculiar characteristics (motivation of patients and investigators, training period, exclusion of early dropouts) the low incidence of drop-outs over a period of $2 \mathrm{yrs}$ is good news on the acceptance of long-term NPPV by patients allowed the treatment and completing an appropriate training period.

\section{Ventilator setting}

Selection of patients, modalities of ventilation [28], types of ventilators [29] and their setting [20] have been claimed to account for conflicting results of NPPV studies [21-24]. Three possible physiological mechanisms of the effects of NPPV in COPD patients have been suggested: 1) the night-time improvement in arterial blood gases [21, 30]; 2) a direct effect on respiratory mechanics; and 3) respiratory muscle unloading, which may lead to a clinical improvement of a supposed but still unproven chronic respiratory fatigue [31].

In the current study, PSV with the addition of an EPAP was used, both set at the patient's comfort. It has been shown that in COPD patients with chronic hypercapnia, mask PSV and EPAP, both set at patients' comfort, led to an improvement in $\mathrm{ABG}$, 


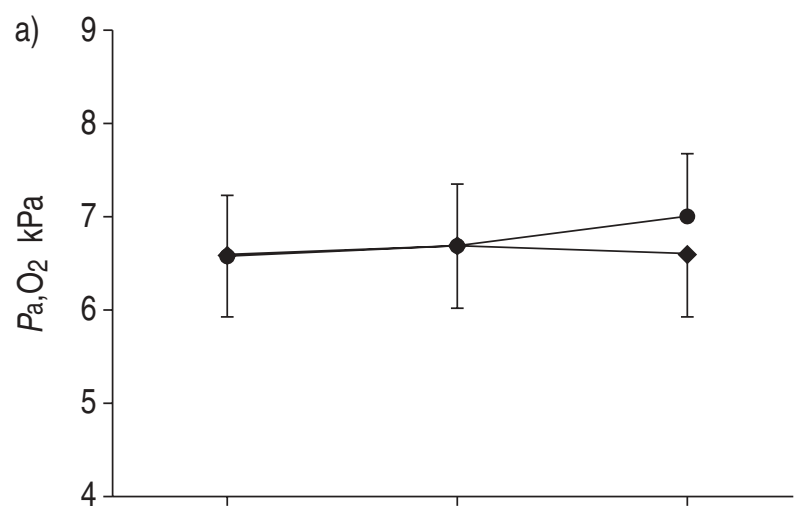

b)
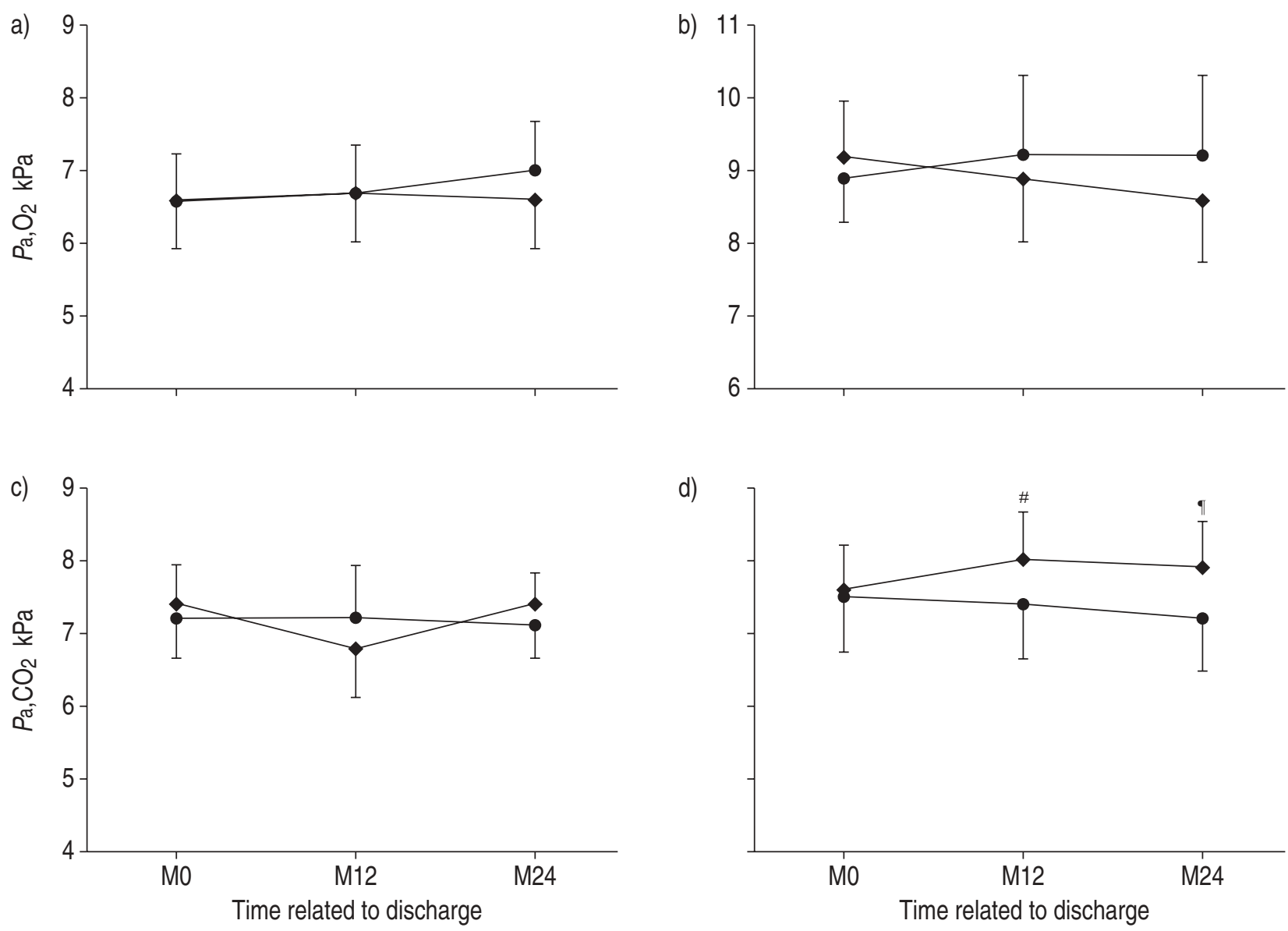

d)

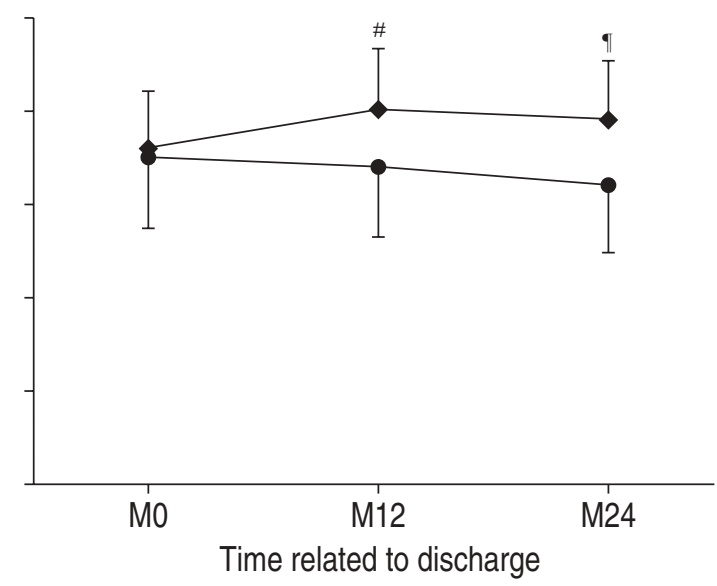

Fig. 2. - Time course of oxygen tension in arterial blood $\left(\mathrm{Pa}_{\mathrm{a}} \mathrm{O}_{2}\right)$ on a) ambient air and on b) usual oxygen, and of carbon dioxide tension in arterial blood $\left(\mathrm{Pa}_{\mathrm{a}}, \mathrm{CO}_{2}\right)$ on c) ambient air and on d) usual oxygen over the study period in the study groups. $\bullet:$ long-term oxygen therapy (LTOT) alone; $\bullet$ : noninvasive positive-pressure ventilation and LTOT. M: month; M0: discharge. ${ }^{\#}$ : $\mathrm{p}=0.005$, treatment effect 2.997, 95\% confidence interval (CI) $0.94-5.05{ }^{\uparrow}{ }^{\top}$ : $\mathrm{p}=0.002$, treatment effect $4.270,95 \%$ CI $1.58-9.96$.

as in this study, and were able to unload significantly the patients' inspiratory muscles, in the same way to a setting tailored to a patient's respiratory muscle effort

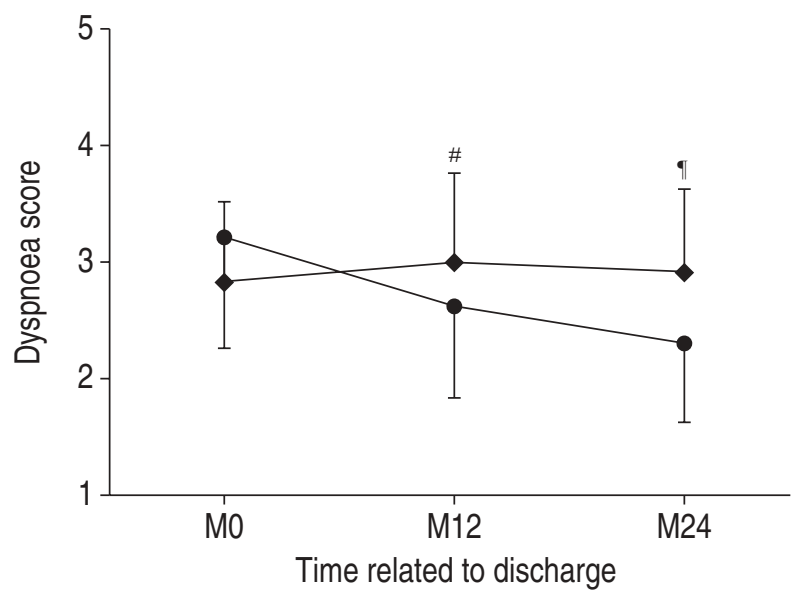

Fig. 3. - Time course of Medical Research Council dyspnoea score over the study period in the study groups. therapy (LTOT); $\bullet$ : noninvasive positive-pressure ventilation and LTOT. ${ }^{\#}$ : $\mathrm{p}=0.048$, treatment effect $0.400,95 \%$ confidence interval (CI) $0.02-0.78 ;{ }^{\uparrow}: \mathrm{p}=0.013$, treatment effect $0.600,95 \%$ CI $0.15-1.05$. and mechanics [20]. In both the chronic [32] and acute [33] settings, the application of some level of positive expiratory pressure during pressure assisted ventilation provided better unloading of the diaphragm, and in some instances of $\mathrm{ABG}$, than inspiratory assistance alone.

\section{Clinical and physiological assessments}

Pulmonary and inspiratory muscle function, exercise tolerance and sleep quality score did not significantly change over time in the two groups, although sleep score showed a trend to improve only in NPPV patients. As the study was not powered to assess differences in sleep quality, the lack of significance in differences in sleep quality might be due to a beta error. With this limitation, the current data confirm and extend, over a longer period of time, the results of GAY et al. [23] and LIN [24]. In the 3-month, shamcontrolled, randomised study by GAY et al. [23], no significant improvement was observed in gas exchange, sleep quality or walking endurance. In the study by LIN [24], NPPV conferred no added benefit over oxygen alone, with regard to oxygenation, ventricular function or sleep quality. 


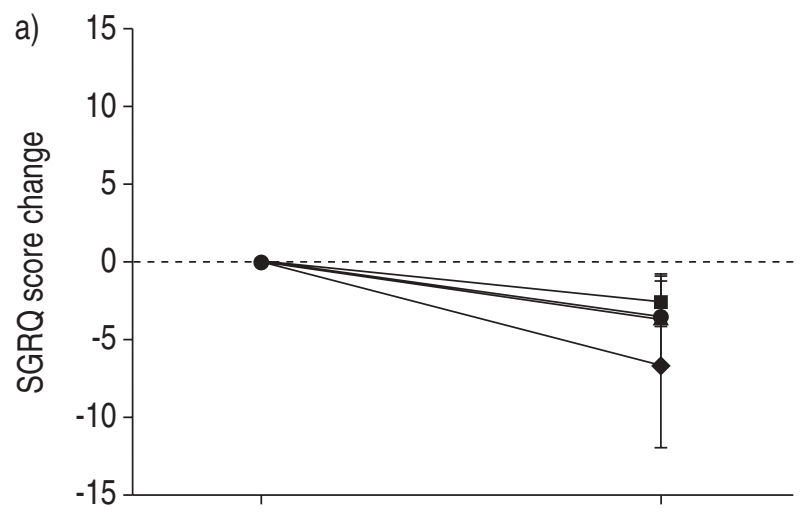

b)
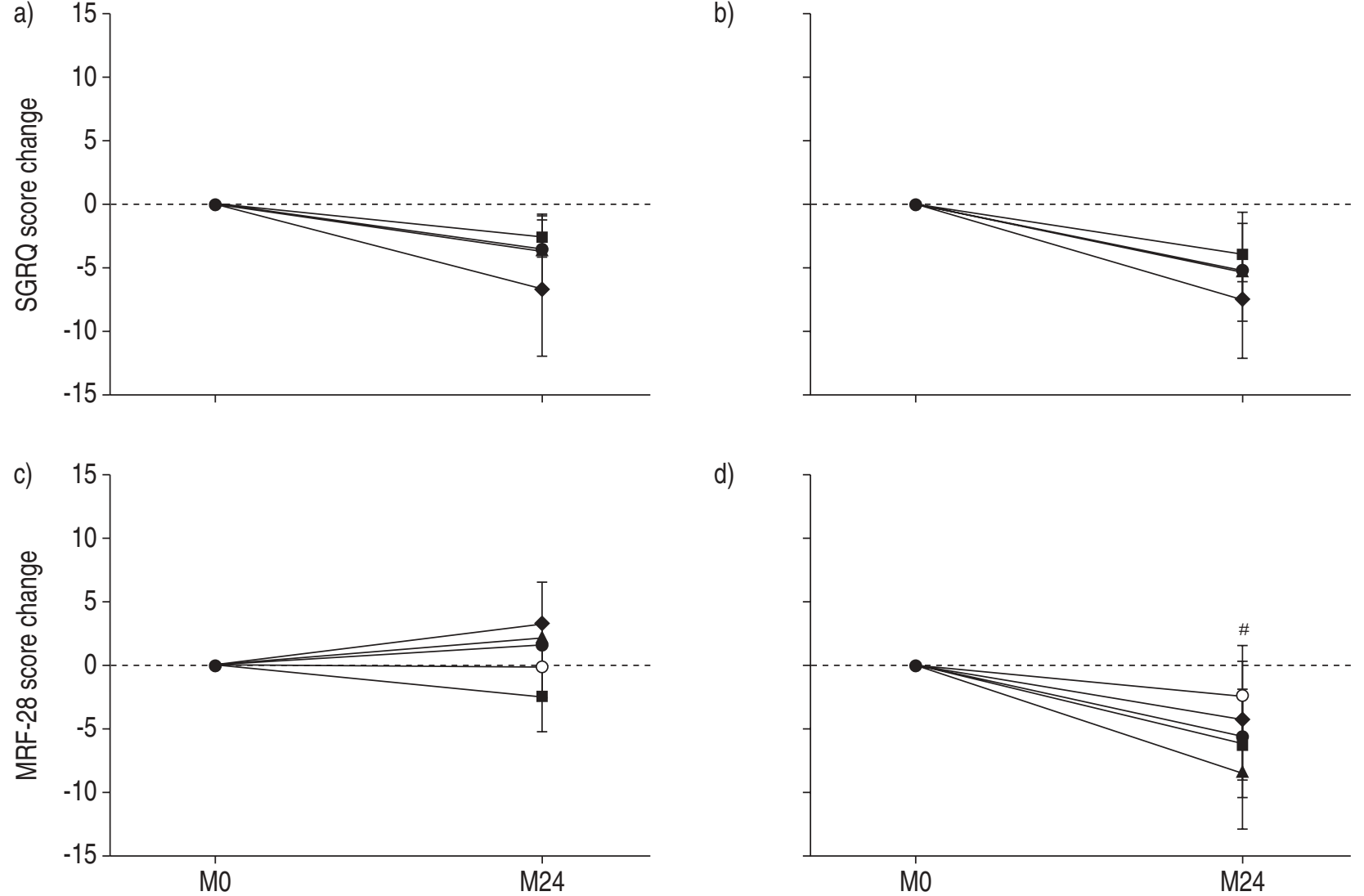

d)

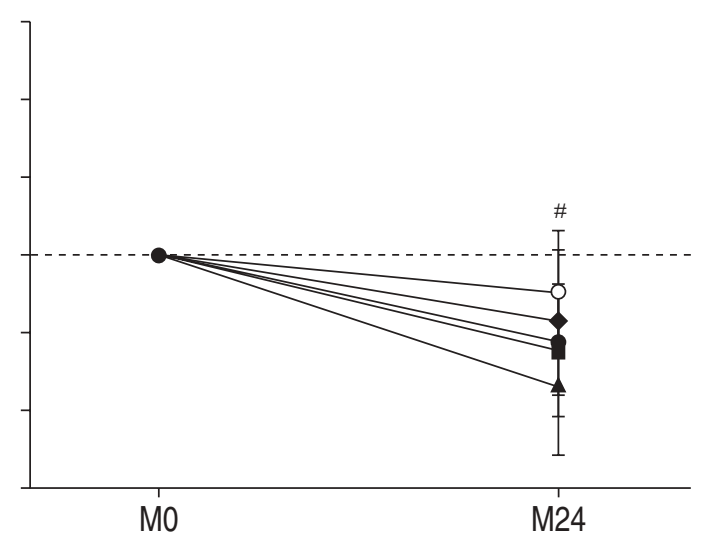

Fig. 4. - Change from baseline in total and dimension scores of St George's Respiratory Questionnaire (SGRQ) (a and b) ( 口: activity; $\mathbf{\Lambda}$ : impact; : total) and Maugeri Foundation Respiratory Failure Questionnaire (MRF-28) (c and d) ( $O$ : cognitive behaviour; : activity; $\mathbf{\square}$ : disability; $\boldsymbol{\Delta}$ : others; : total). M0: discharge; M24: 24 months after discharge. Group comparison for changes from baseline in total SGRQ score was not significant, $\mathrm{p}=0.554{ }^{\#}{ }^{\#}$ : $\mathrm{p}=0.041$, treatment effect $7.100,95 \%$ confidence interval $0.13-4.07$.

Due to the lack of information from previous studies on long-term effects of NPPV on other outcome measures (hospitalisations, HRQL, etc.), $\mathrm{Pa}, \mathrm{CO}_{2}$ was the only variable chosen to power the study. Although there was no within or between group difference in $\mathrm{ABG}$, assessed during breathing of ambient air, an original result of the current study is the improvement over time in $\mathrm{Pa}_{\mathrm{a}} \mathrm{CO}_{2}$ during breathing of the usual oxygen inspiratory fraction observed with NPPV+LTOT compared to LTOT alone. This result is particularly interesting in the light of the fact that breathing oxygen is the common condition of these patients (19-20 h a day for both groups). A 3-month crossover trial by MEecham-Jones et al. [21] found that nocturnal and daytime gas exchange, total sleep time, and symptoms improved during NPPV use. The degree of improvement in day-time $\mathrm{Pa}, \mathrm{CO}_{2}$ was correlated with changes in mean overnight values, indicating that control of nocturnal hypoventilation was the key factor for the success of ventilatory support.

\section{Health-related quality of life}

After 2 yrs the SGRQ total score, in both groups, showed a mean slight improvement $(4 \%, 5 \%)$ at the limit of clinical significance, mainly due to an improvement in symptoms [17] (fig. 4a and b).
MeEcham-Jones et al. [21] found an NPPV-associated improvement in SGRQ scores in their 3-month study. In the current study, unlike the SGRQ, the MRF-28 total score showed an improvement only in NPPV group (fig. 4c and d). The MRF-28 is a questionnaire specifically designed to evaluate HRQL in patients with chronic respiratory failure [18]. In this regard, this is the first study to show a clear long-term benefit of the addition of NPPV+LTOT over LTOT alone in HRQL. At the same time, the lack of correspondence in results between the SGRQ and MRF-28 indicates the need to evaluate HRQL with specific instruments, tailored to patients' condition.

\section{Hospitalisations}

Hospital admissions showed only a nonsignificant trend to be lower in the NPPV group during followup. Total hospital admissions increased by $27 \%$ in the LTOT group but decreased by $45 \%$ in the NPPV+ LTOT group (when comparing the follow-up with the follow-back periods). At the same time, number of ICU admissions changed over time by $-20 \%$ and $-75 \%$ in LTOT and NPPV groups, respectively. These data confirm the preliminary results of the European multicentric study of NPPV (with volume-cycled 
ventilators) in severe hypercapnic COPD, showing that NPPV is well accepted and is associated with a reduction in hospitalisation for acute-on-chronic ventilatory failure [34]. CASANOVA et al. [25], in a 1 -yr randomised study of NPPV+standard care versus standard care alone (93\% with LTOT) found that, given an identical survival and acute exacerbations rate, the number of hospital admissions fell significantly in the third month in the NPPV group (5 versus $15 \%$ ) but remained unchanged after the third month. The only benefits observed in the NPPV group were a reduction in dyspnoea and an improvement of one of the neuropsychological tests on the 6th month [25].

Exacerbations treated in the community and extra therapy taken at exacerbations were not recorded in the current study. Therefore, evaluation of healthcare resources presents an important limitation.

\section{Survival}

Although the sample size of this study was not powered to evaluate survival, survival rate was similar in the two groups. As yet no study has provided convincing evidence that survival in COPD is prolonged by NPPV. The continuation curve for patients with COPD, in an English follow-up study [35], was virtually identical to that of survival in patients with COPD using LTOT in the Nocturnal Oxygen Therapy Trial [36], suggesting that any survival benefit of NPPV over that of LTOT alone is minimal. The current study and the preliminary results of the European study [34] confirm this view, although the latter study suggests that patients $>65$ yrs of age may have a slight improvement in survival.

In conclusion, this 2-yr prospective, randomised, controlled study shows that the addition of noninvasive positive-pressure ventilation to long-term oxygen therapy in stable chronic obstructive pulmonary disease patients with chronic ventilatory failure is able to: 1) improve daytime carbon dioxide in arterial blood during oxygen breathing; and 2) improve dyspnoea and health-related quality of life. The data from this prospective trial would help in the design of a larger, possibly European, and longer prospective study on the effects of noninvasive positive-pressure ventilation in patients with chronic ventilatory failure, due to advanced chronic obstructive pulmonary disease. Due to the socioeconomic, individual and clinical relevance of chronic ventilatory failure in chronic obstructive pulmonary disease, the confirmation of a significant reduction in hospital and intensive care unit stay would have important implications for the management of advanced chronic obstructive pulmonary disease in the home setting. Further work is also required to evaluate the effect of noninvasive positivepressure ventilation on reducing frequency and severity of chronic obstructive pulmonary disease exacerbation.

Acknowledgements. The authors would like to thank Link Italia $\mathbb{R}$ (Service of Biostatistics) for database and data entry assistance; R. Allpress and M. Bresciani for linguistic revision of the manuscript; Markos-Mefar by Air
Liquide Group Italia for technical aid and an unrestricted educational grant; Boehringer Ingelheim for an unrestricted educational grant. Participating centres and investigators. Cagliari (A. Murgia, R. DeMurtas), Cava dei Tirreni (M. Polverino, M.A. Grisolia), Cittadella, (A. Marcolongo), Crema (M. Confalonieri), Firenze (M. Gorini, G. Villella), Gaiato (G. Garuti), Gussago (E. Clini, M. Vitacca), Mantova (C.Scarduelli), Milano 01 (S. Amaducci, A. Iuliano), Milano 02 (M. Sergi, M. Rizzi), Montescano (S. Nava), Napoli (F. Squillante, R. Cassandro), Padova (M. Bevilacqua), Palermo (S. Marchese, A. LoCoco), Pavia (I. Cerveri, A. Pasi), Perugia (M. Dottorini, S. Baglioni, P. Ferranti, R.Tazza), Pisa (A. Palla, M. Desideri), Rouen-F (J.F. Muir), Seregno (S. Damato, P. Marino), Udine (A. Peratoner), Veruno (S. Zaccaria).

\section{References}

1. Pauwels RA, Buist AS, Calverley PMA, Jenkins CR, Hurd SS, on behalf of the GOLD Scientific Committee. Global strategy for the diagnosis, management and prevention of chronic obstructive lung disease. NHLBI/WHO global initiative for chronic obstructive lung disease (GOLD) workshop summary. Am J Respir Crit Care Med 2001; 163: 1256-1276.

2. Plant PK, Owen JL, Elliott MW. One year period prevalence study of respiratory acidosis in acute exacerbations of COPD: implications for the provision of non-invasive ventilation and oxygen administration. Thorax 2000; 55: 550-554.

3. Vitacca M, Foglio K, Scalvini S, Marangoni S, Quadri A, Ambrosino N. Time course of pulmonary function before admission into ICU. A two year retrospective study of COLD patients with hypercapnia. Chest 1992; 102: 1737-1741.

4. Seemungal TAR, Donaldson GC, Paul EA, et al. Effect of exacerbation on quality of life in patients with chronic obstructive pulmonary disease. Am J Respir Crit Care Med 1998; 157: 1418-1422.

5. Medical Research Council Working Party. Long-term domiciliary oxygen therapy in chronic hypoxic cor pulmonale complicating chronic bronchitis or emphysema. Lancet 1981; 1: 681-686.

6. Mehta S, Hill NS. Noninvasive ventilation. Am J Respir Crit Care Med 2001; 163: 540-577.

7. Cuvelier A, Muir JF. Noninvasive ventilation and obstructive lung diseases. Eur Respir J 2001; 17: 12711281.

8. Rossi A, Hill NS. Pro-con debate: noninvasive ventilation has been shown to be effective/ineffective in stable COPD. Am J Respir Crit Care Med 2000; 161: 688-691.

9. ATS statement. Standards for the diagnosis and care of patients with chronic obstructive pulmonary disease. Am J Respir Crit Care Med 1995; 152: S77S120.

10. Medical Research Council Committee on research into chronic bronchitis. Instructions for use of the questionnaire on respiratory symptoms. Devon, WJ. Holman, 1966.

11. European Respiratory Society. Standardized lung function testing. Eur Respir J 1993; 6: Suppl. 16, $1-100$. 
12. Quanjer $\mathrm{PhH}$. Standardized lung function testing. Bull Eur Physiopathol Respir 1983; 19: Suppl. 5, 22-27.

13. Black LF, Hyatt RE. Maximal respiratory pressures: normal values and relationship to age and sex. Am Rev Respir Dis 1969; 99: 696-702.

14. Butland RJA, Pang J, Gross ER, Woodcock AA, Geddes DM. Two, six and 12 minute walking tests in respiratory disease. $B M J$ 1982; 284: 1607-1608.

15. Rechtschaffen A, Kales A. A manual of standardized terminology, techniques and scoring systems for sleep stages of human subjects. NIH publication no.204. Bethesda, MD, National Institute of Neurological disease and blindness, 1968.

16. Meurice GC, Dore P, Paquereau J, et al. Predictive factors of long-term compliance with nasal CPAP treatment in sleep apnea syndrome. Chest 1994; 105: 429-433.

17. Jones PW, Quirk FH, Baveystock CM, Littlejohns P. A self-complete measure of health status for chronic airflow limitation. Am Rev Respir Dis 1992; 145: 13211327.

18. Carone M, Bertolotti G, Anchisi F, et al. Analysis of factors that characterize health impairment in patients with chronic respiratory failure. Eur Respir J 1999; 13: 1293-1300.

19. Ferguson GT, Gilmartin M. $\mathrm{CO}_{2}$ rebreathing during BiPAP ventilatory assistance. Am J Respir Crit Care Med 1995; 151: 1126-1135.

20. Vitacca M, Nava S, Confalonieri M, et al. The appropriate setting of noninvasive pressure support ventilation in stable COPD patients. Chest 2000; 118 : 1286-1293.

21. Meecham-Jones DJ, Paul EA, Jones PW, Wedzicha JA. Nasal pressure support ventilation plus oxygen compared with oxygen therapy alone in hypercapnic COPD. Am J Respir Crit Care Med 1995; 152: 538-544.

22. Strumpf DA, Millman RP, Carlisle CC, et al. Nocturnal positive-pressure ventilation via nasal mask in patients with severe chronic obstructive pulmonary disease. Am Rev Respir Dis 1991; 144: 1234-1239.

23. Gay PC, Hubmayr RD, Stroetz RW. Efficacy of nocturnal nasal ventilation in stable severe chronic obstructive pulmonary disease during a 3 month controlled trial. Mayo Clin Proc 1996; 71: 533-542.

24. Lin CC. Comparison between nocturnal nasal positive pressure ventilation combined with oxygen therapy and oxygen monotherapy in patients with severe COPD. Am J Respir Crit Care Med 1996; 154: 353358.

25. Casanova C, Celli BR, Tost L, et al. Long-term controlled trial of nocturnal nasal positive pressure ventilation in patients with severe COPD. Chest 2000; 118: 1582-1590.

26. Clini E, Sturani C, Porta R, et al. Outcome of COPD patients performing nocturnal non-invasive mechanical ventilation. Respir Med 1998; 92: 1215-1222.

27. Criner GJ, Brennan K, Travaline JM, Kreimer D. Efficacy and compliance with noninvasive positive pressure ventilation in patients with chronic respiratory failure. Chest 1999; 116: 667-675.

28. Meecham Jones DJ, Wedzicha JA. Comparison of pressure and volume preset nasal ventilator systems in stable chronic respiratory failure. Eur Respir J 1993; 6: 1060-1064.

29. Bunburaphong T, Imanaka H, Nishimura M, Hess D, Kacmarek PM. Performance characteristics of bilevel pressure ventilators. A lung model study. Chest 1997; 111: 1050-1060.

30. Elliott MW, Mulvey DA, Moxham J, Green M, Branthwaite MA. Domiciliary nocturnal nasal intermittent positive pressure ventilation in COPD: mechanisms underlying changes in arterial blood gas tension. Eur Respir J 1991; 4: 1044-1052.

31. Shapiro SH, Ernst P, Gray-Donald K, et al. Effect of negative pressure ventilation in severe chronic obstructive pulmonary disease. Lancet 1992; 340: 1425-1429.

32. Nava S, Ambrosino N, Rubini F, et al. Effect of nasal pressure support ventilation and external PEEP on diaphragmatic activity in patients with severe stable COPD. Chest 1993; 103: 143-150.

33. Appendini L, Patessio A, Zanaboni S, et al. Physiological effects of positive end expiratory pressure and mask pressure support during exacerbations of chronic obstructive pulmonary disease. Am J Respir Crit Care Med 1994; 149: 1069-1076.

34. Muir JF, De la Salmoniere P, Cuvelier A, and the European Group. Survival of severe hypercapnic COPD under long-term home mechanical ventilation with NPPV plus oxygen versus oxygen therapy alone: results of a European multicenter study. Am J Respir Crit Care Med 1999; 159: A295.

35. Simonds AK, Elliott MW. Outcome of domiciliary nasal intermittent positive pressure ventilation in restrictive and obstructive disorders. Thorax 1995; 50: 604-609.

36. Nocturnal Oxygen Therapy Trial Group. Continuous or nocturnal oxygen therapy in hypoxemic chronic obstructive lung disease: a clinical trial. Ann Intern Med 1980; 93: 391-398. 